\title{
Sex-Specific Causal Relations between Steroid Hormones and Obesity-A Mendelian Randomization Study
}

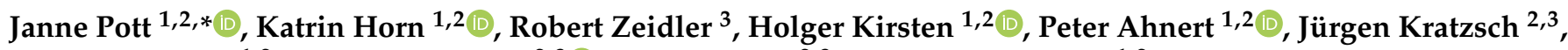 \\ Markus Loeffler ${ }^{1,2}$, Berend Isermann ${ }^{2,3}{ }^{(0)}$, Uta Ceglarek ${ }^{2,3}$ and Markus Scholz ${ }^{1,2, *}$
}

1 Institute for Medical Informatics, Statistics and Epidemiology, Medical Faculty, University of Leipzig, 04107 Leipzig, Germany; katrin.horn@imise.uni-leipzig.de (K.H.); holger.kirsten@imise.uni-leipzig.de (H.K.); peter.ahnert@imise.uni-leipzig.de (P.A.); markus.loeffler@imise.uni-leipzig.de (M.L.)

2 LIFE Research Center for Civilization Diseases, Medical Faculty, University of Leipzig, 04103 Leipzig, Germany; juergen.kratzsch@medizin.uni-leipzig.de (J.K.); berend.isermann@medizin.uni-leipzig.de (B.I.); Uta.Ceglarek@medizin.uni-leipzig.de (U.C.)

3 Institute of Laboratory Medicine, Clinical Chemistry and Molecular Diagnostics, University Hospital Leipzig, 04103 Leipzig, Germany; robert.zeidler@googlemail.com

* Correspondence: janne.pott@medizin.uni-leipzig.de (J.P.); markus.scholz@medizin.uni-leipzig.de (M.S.)

check for updates

Citation: Pott, J.; Horn, K.; Zeidler, R.; Kirsten, H.; Ahnert, P.; Kratzsch, J.; Loeffler, M.; Isermann, B.; Ceglarek, U.; Scholz, M. Sex-Specific Causal Relations between Steroid Hormones and Obesity-A Mendelian Randomization Study. Metabolites 2021, 11, 738. https://doi.org/ 10.3390/metabo11110738

Academic Editor: Anna Floegel

Received: 14 October 2021

Accepted: 26 October 2021

Published: 28 October 2021

Publisher's Note: MDPI stays neutral with regard to jurisdictional claims in published maps and institutional affiliations.

Copyright: (c) 2021 by the authors. Licensee MDPI, Basel, Switzerland. This article is an open access article distributed under the terms and conditions of the Creative Commons Attribution (CC BY) license (https:// creativecommons.org/licenses/by/ $4.0 /)$.

\begin{abstract}
Steroid hormones act as important regulators of physiological processes including gene expression. They provide possible mechanistic explanations of observed sex-dimorphisms in obesity and coronary artery disease (CAD). Here, we aim to unravel causal relationships between steroid hormones, obesity, and CAD in a sex-specific manner. In genome-wide meta-analyses of four steroid hormone levels and one hormone ratio, we identified 17 genome-wide significant loci of which 11 were novel. Among loci, seven were female-specific, four male-specific, and one was sex-related (stronger effects in females). As one of the loci was the human leukocyte antigen (HLA) region, we analyzed HLA allele counts and found four HLA subtypes linked to 17-OH-progesterone (17-OHP), including HLA-B* $14^{*} 02$. Using Mendelian randomization approaches with four additional hormones as exposure, we detected causal effects of dehydroepiandrosterone sulfate (DHEA-S) and 17-OHP on body mass index (BMI) and waist-to-hip ratio (WHR). The DHEA-S effect was stronger in males. Additionally, we observed the causal effects of testosterone, estradiol, and their ratio on WHR. By mediation analysis, we found a direct sex-unspecific effect of 17-OHP on CAD while the other four hormone effects on CAD were mediated by BMI or WHR. In conclusion, we identified the sex-specific causal networks of steroid hormones, obesity-related traits, and CAD.
\end{abstract}

Keywords: steroid hormones; sexual dimorphism; genome-wide association analysis; Mendelian randomization; coronary artery disease; obesity

\section{Introduction}

Male sex is an independent risk factor for cardiovascular disease (CVD), but the underlying molecular mechanisms are not fully understood. Genome-wide association studies have identified several risk loci in the autosomes [1], but none on chromosome X [2]. This indicates that the observed sex-dimorphism of CVD risk is not primarily driven by gonosomal genetics. Since steroid metabolism is highly sex-specific, a causal relationship to atherosclerosis risk can be hypothesized, but the underlying molecular mechanisms are only partly understood.

There are some studies supporting this relationship: estradiol (E2) was suspected of having a cardio-protective effect before menopause [3-5] and levels of dehydroepiandrosterone sulfate (DHEA-S) were found to be different between coronary artery disease (CAD) patients and controls [6] with lower DHEA-S levels associated with higher cardiovascular disease mortality [7]. Despite these correlations, the causality of steroid hormones on CVD has not yet been investigated in detail. 
Obesity is a disease defined by excessive fat accumulation that might impair health [8]; it also displays a strong sexual dimorphism in particular with respect to body fat distribution mediated by steroid hormones $[9,10]$. Two common measures of obesity are body mass index (BMI) and waist-to-hip ratio (WHR). While BMI is highly correlated to the percentage of body fat [11], WHR takes differences in body shape into account. WHR adjusted for BMI (WHRadj) has been shown to be a good predictor of cardiovascular events such as ischaemic heart disease [12]. Recent sex-stratified genome-wide association meta-analyses (GWAMA) of BMI and WHRadj found 346 associated loci of which one third was sex-related, mostly with stronger effects in women [13].

It has been shown that steroid hormone signaling is relevant in adipose tissue (AT) regulation [14], e.g., aldosterone receptor signaling induces abnormal secretion of adipokines [15]. Steroid-hormone-converting enzymes have an effect on AT function [16] and their gene expression in AT changes in response to exercise and diet [17]. A cross-sectional study in adult males showed an association between WHR and sex steroid hormones, including the ratio of testosterone (T) and estradiol (E2) [18]. The T/E2 ratio has been suggested as a parameter of the disturbance of the physiological balance of these hormones and might be more meaningful than the absolute quantities of T and E2 [19].

While the causal link of obesity to CAD is well established [20], the relation between steroid hormones and their effects on BMI, WHR, and CAD is less analyzed regarding causality. A longitudinal analysis found no influence of baseline sex hormone levels on changes in obesity measures, but that body composition might affect hormone levels [18]. Moreover, it has not yet been studied how obesity might mediate the causal effect of hormones on CAD. Here, we attempt to clarify the relationship between steroids, obesity, and CAD by a comprehensive Mendelian randomization (MR) network analysis. Assuming allelic randomization takes place during meiosis and three key assumptions are met, this method estimates the causal effect of life-long small changes of an exposure on an outcome [21].

In the present study, we first validate previously published genetic loci associated with steroid hormones [22] and add novel variants as instrumental variables for MR. Then, we use these instruments in bivariate MR to test the causal links between hormones and obesity in both directions. Finally, we examine if there is an effect of steroid hormones on CAD and test whether it is mediated by obesity. A graphical summary of all MR analyses is given in Figure 1. 


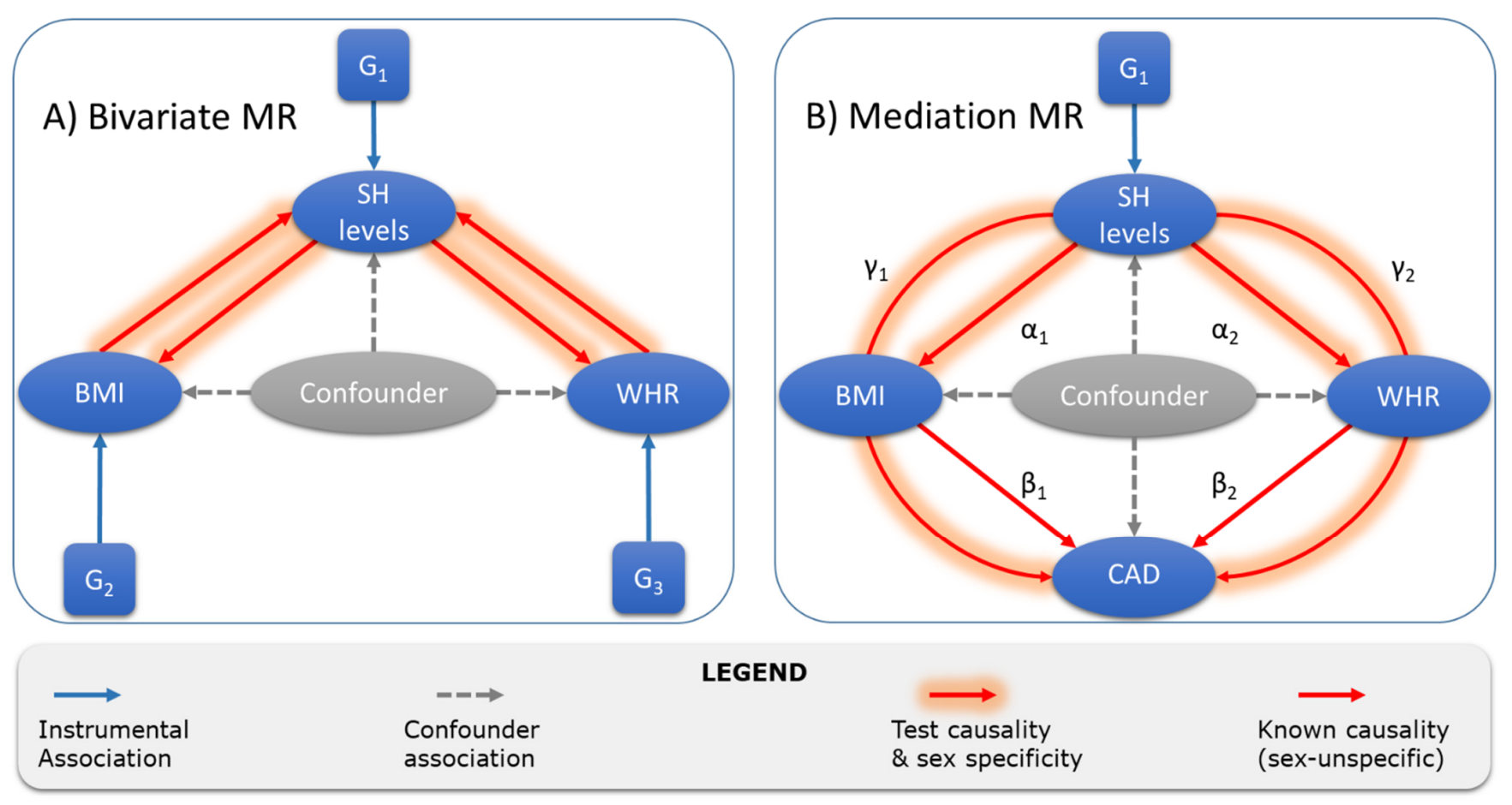

Figure 1. Overview of Mendelian randomization and mediation analyses of the present study. After the identification of valid instruments $\mathrm{G}_{1}$ for steroid hormones $(\mathrm{SH})$, we performed two MR analyses. (A) First, we conducted bivariate MRs testing causality between SH and the two obesity traits, BMI and WHR. Sex-specific summary statistics and instruments for BMI and WHR were taken from Pulit et al. [13] $\left(\mathrm{G}_{2}\right.$ and $\left.\mathrm{G}_{3}\right)$. (B) Then, we tested for direct (not shown) and indirect effects $\left(\gamma_{i}\right)$ of SH on CAD using causal effect estimates of SH on BMI and WHR $\left(\alpha_{i}\right)$ and of BMI and WHR on CAD ( $\beta_{i}$, taken from Zhang et al. [20]). CAD summary statistics were obtained from van der Harst et al. [1] (sex-unspecific).

\section{Results}

\subsection{GWAMA}

To validate known and discover novel instruments for our MR analyses, we performed genome-wide association meta-analyses (GWAMA) of the levels of four hormones, namely progesterone (P4), hydroxyprogesterone (17-OHP), androstenedione (A4), and aldosterone (Aldo) in two independent studies: LIFE-Heart (1357 males, 711 females) [23] and LIFEAdult (863 males, 618 females) [24]. As the ratio of testosterone to estradiol (T/E2) is suggested a parameter of the disturbance of physiological balance, we analyzed T/E2 as well and searched for additional loci. In Table 1, the baseline characteristics of participants of both studies are given. Genetic data of each study were imputed to 1000 Genomes Phase 3 (European ancestry) [25], and single study association statistics were obtained using the same protocol (see Methods).

We calculated fixed-effect meta-analysis models (FEM) and applied SNP filters for minor allele frequency (MAF, sample size weighted MAF $\geq 1 \%$ ), imputation info score (minimal score of studies $\geq 0.8$ ), and heterogeneity of meta-analysis results $\left(\mathrm{I}^{2} \leq 0.9\right)$. A total of 10.9 Mio SNPs remained for evaluation, for which we did not observe signs of general inflation of test-statistics ( $\lambda$ in between 0.99 and 1.01). Genome-wide results across all hormones for the combined setting as well as the male- and female-stratified setting are shown in Figure 2. Across all settings and hormones, we detected 35 genome-wide significant and independent SNPs $\left(p<5 \times 10^{-8}\right.$ and pairwise LD $\left.{ }^{2}<0.1\right)$, of which 17 were best-associated in the combined setting, 11 in the male-stratified setting, and 7 in the female-stratified setting. Hits can be summarized to 16 unique genomic loci plus the major histocompatibility complex (MHC) stretching over three cytobands on chromosome 6 (6p21.32, 6p21.33, and 6p22.1). We searched for genetic sex interactions of all genome-wide significant lead SNPs and applied hierarchical FDR correction to adjust for multiple testing (see Methods). Summary statistics, annotations, and interaction results can be found in Tables S1-S5. 


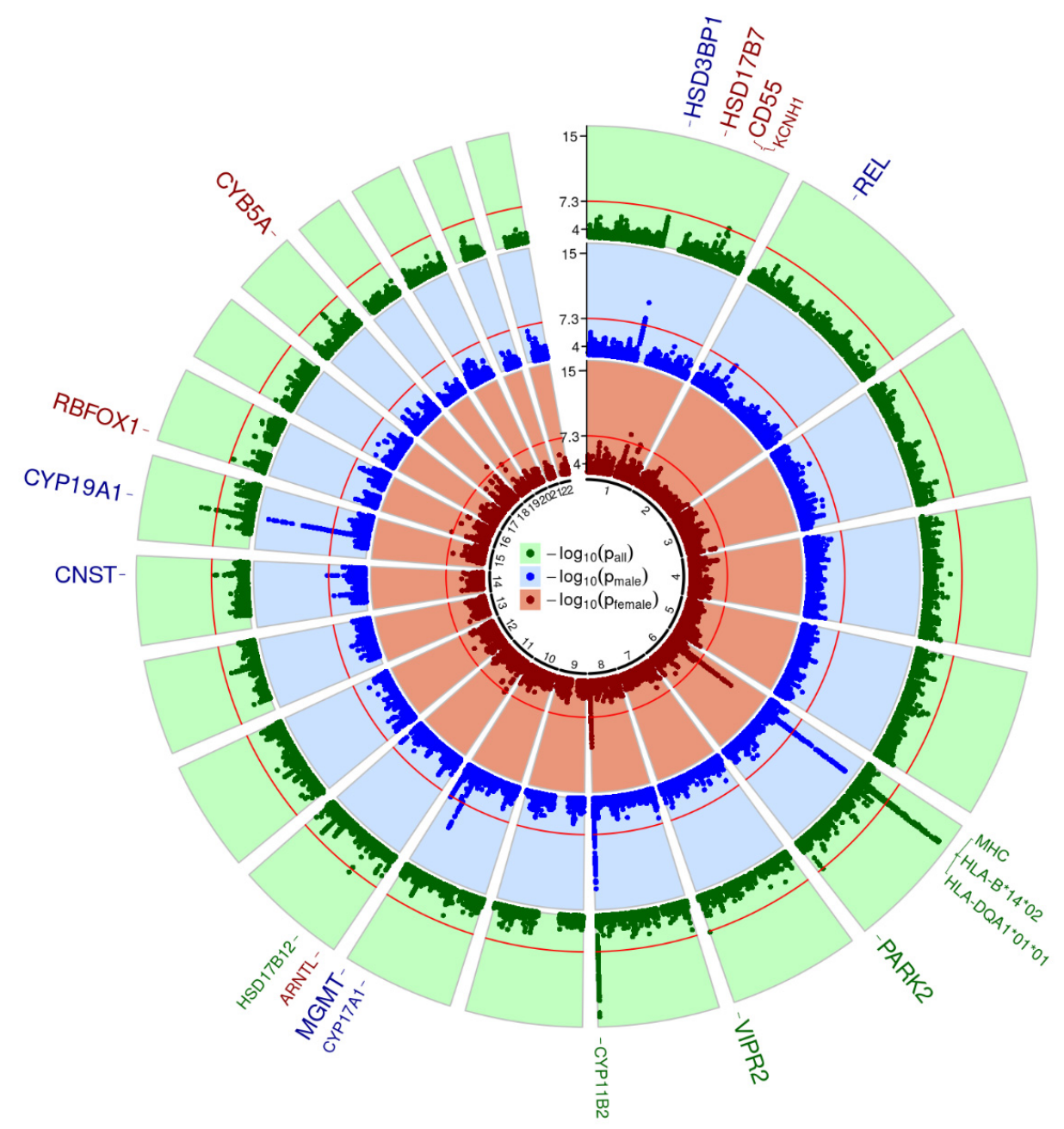

Figure 2. Circular Manhattan plot of GWAMA results. Minimal $p$-values across analyzed traits are presented for each analysis group (green-all samples; blue-male only; red-female only). In each Manhattan circle, the genome-wide significance threshold of $5 \times 10^{-8}$ is given a red circle $\left(-\log _{10}\right.$ transformed). Loci with genome-wide significant SNPs are named outside the circles. They are colored according to the analysis setting showing the highest significance for that locus. Increased font size indicates novelty, while replicated loci are displayed in smaller font size.

Table 1. Study characteristics of LIFE-Adult and LIFE-Heart. Binary variables other than sex are given in absolute counts and percentage. Continuous variables are reported by mean (SD) or median [range]. Abbreviations: CAD, coronary artery disease; BMI, body mass index; WHR, waist-hip-ratio; P4, progesterone; 17-OHP, hydroxyprogesterone; A4, androstenedione; Aldo, aldosterone; T/E2, ratio of testosterone and estradiol.

\begin{tabular}{ccccccc}
\hline & & LIFE-Adult & & \multicolumn{2}{c}{ LIFE-Heart } \\
\hline Parameter & Combined & Males & Females & Combined & Males & Females \\
\hline Sex & 1481 & $863(58.3)$ & $618(41.7 \%)$ & 2068 & $1357(65.6 \%)$ & $711(34.4 \%)$ \\
\hline Age, y & $63.7(7.8)$ & $64.1(7.8)$ & $63.2(7.7)$ & $63.0(10.9)$ & $62.1(11.1)$ & $64.8(10.3)$ \\
\hline Current smoker & $242(16.7 \%)$ & $148(17.5 \%)$ & $94(15.6 \%)$ & $401(19.4 \%)$ & $318(23.4 \%)$ & $83(11.7 \%)$ \\
\hline Type 2 diabetes & $267(23.9 \%)$ & $180(26.5 \%)$ & $87(19.9 \%)$ & $644(31.2 \%)$ & $424(31.3 \%)$ & $220(30.9 \%)$ \\
\hline CAD & - & - & - & $836(41.9 \%)$ & $646(49.2 \%)$ & $190(27.8 \%)$ \\
\hline BMI, $\mathrm{kg} / \mathrm{m}^{2}$ & $27.9(4.5)$ & $28.0(4.1)$ & $27.7(5.1)$ & $29.7(5.0)$ & $29.5(4.6)$ & $30.1(5.7)$ \\
\hline WHR & $0.96(0.08)$ & $1.01(0.06)$ & $0.89(0.06)$ & $0.97(0.09)$ & $1.02(0.06)$ & $0.89(0.06)$ \\
\hline P4 ${ }^{1}, \mathrm{nmol} / \mathrm{L}$ & 0.26 & 0.32 & 0.21 & 0.34 & 0.35 & {$[0.28-0.44]$} \\
\hline
\end{tabular}


Table 1. Cont.

\begin{tabular}{|c|c|c|c|c|c|c|}
\hline \multirow[b]{2}{*}{ Parameter } & \multicolumn{3}{|c|}{ LIFE-Adult } & \multicolumn{3}{|c|}{ LIFE-Heart } \\
\hline & Combined & Males & Females & Combined & Males & Females \\
\hline 17-OHP, nmol/L & $\begin{array}{c}1.66 \\
{[0.87-2.65]}\end{array}$ & $\begin{array}{c}2.34 \\
{[1.75-3.20]}\end{array}$ & $\begin{array}{c}0.80 \\
{[0.55-1.14]}\end{array}$ & $\begin{array}{c}1.36 \\
{[0.77-2.14]}\end{array}$ & $\begin{array}{c}1.78 \\
{[1.24-2.41]}\end{array}$ & $\begin{array}{c}0.64 \\
{[0.42-0.94]}\end{array}$ \\
\hline $\mathrm{A} 4, \mathrm{nmol} / \mathrm{L}$ & $\begin{array}{c}2.41 \\
{[1.79-3.19]}\end{array}$ & $\begin{array}{c}2.65 \\
{[2.03-3.38]}\end{array}$ & $\begin{array}{c}2.03 \\
{[1.46-2.86]}\end{array}$ & $\begin{array}{c}2.16 \\
{[1.58-2.97]}\end{array}$ & $\begin{array}{c}2.32 \\
{[1.75-3.11]}\end{array}$ & $\begin{array}{c}1.85 \\
{[1.33-2.66}\end{array}$ \\
\hline Aldo, pmol/L & $\begin{array}{c}131 \\
{[83-195]}\end{array}$ & $\begin{array}{c}122 \\
{[83-186]}\end{array}$ & $\begin{array}{c}145 \\
{[92-207]}\end{array}$ & $\begin{array}{c}112 \\
{[61-186]}\end{array}$ & $\begin{array}{c}112 \\
{[60-186]}\end{array}$ & $\begin{array}{c}113 \\
{[62-187]}\end{array}$ \\
\hline $\mathrm{T} / \mathrm{E} 2^{2}$ & $\begin{array}{c}86.3 \\
{[16.3-187.3]}\end{array}$ & $\begin{array}{c}182.5 \\
{[131.2-250]}\end{array}$ & $\begin{array}{c}15.2 \\
{[4.7-31.0]}\end{array}$ & $\begin{array}{c}144.5 \\
{[66.9-353.3]}\end{array}$ & $\begin{array}{c}230.0 \\
{[141.6-891]}\end{array}$ & $\begin{array}{c}51.6 \\
{[25.3-78.7]}\end{array}$ \\
\hline
\end{tabular}

${ }^{1}$ Using 553 additional female samples in LIFE-Adult. ${ }^{2}$ Using ECLIA measurements for $N=5575$ (2928 males, 2648 females) in LIFE-Adult.

Eleven of these loci have not yet been described for the respective traits and, hence, are considered as novel findings. For P4, there were three novel loci: CD55 at 1q32.2 (female-specific) [26], VIPR2 at 7q36.3 (sex-related, stronger effect in females) [27], and RBFOX1 at 16p13.3 (female-specific) [28]. For 17-OHP, we also detected three novel hits: HSD3B1 at 1p12 (male-specific) [22], REL at 2p15 (sex-unspecific) [29], and CYB5A at 18q22.3 (male-specific) [30]. There was only one novel locus associated with A4: MGMT at 10q26.3 (male-specific) [31-33]. For the first time, we detected two hits for Aldo: HSD17B7 at 1q23.3 (female-specific) [22], and in the gene dessert at 14q31.2 (male-specific, transeQTL of CNST) [34]. Finally, there were two novel loci for T/E2: CYP19A1 at 15q21.2 (sex-unspecific) [13,22,35], and PARK2 at 6q26 (sex-unspecific) [36]. A summary of these results is presented in Table 2 , and a scatter plot of effect sizes in males and females is shown in Figure 3. A more detailed presentation, including a discussion of plausible candidate genes is provided in the supplemental materials.

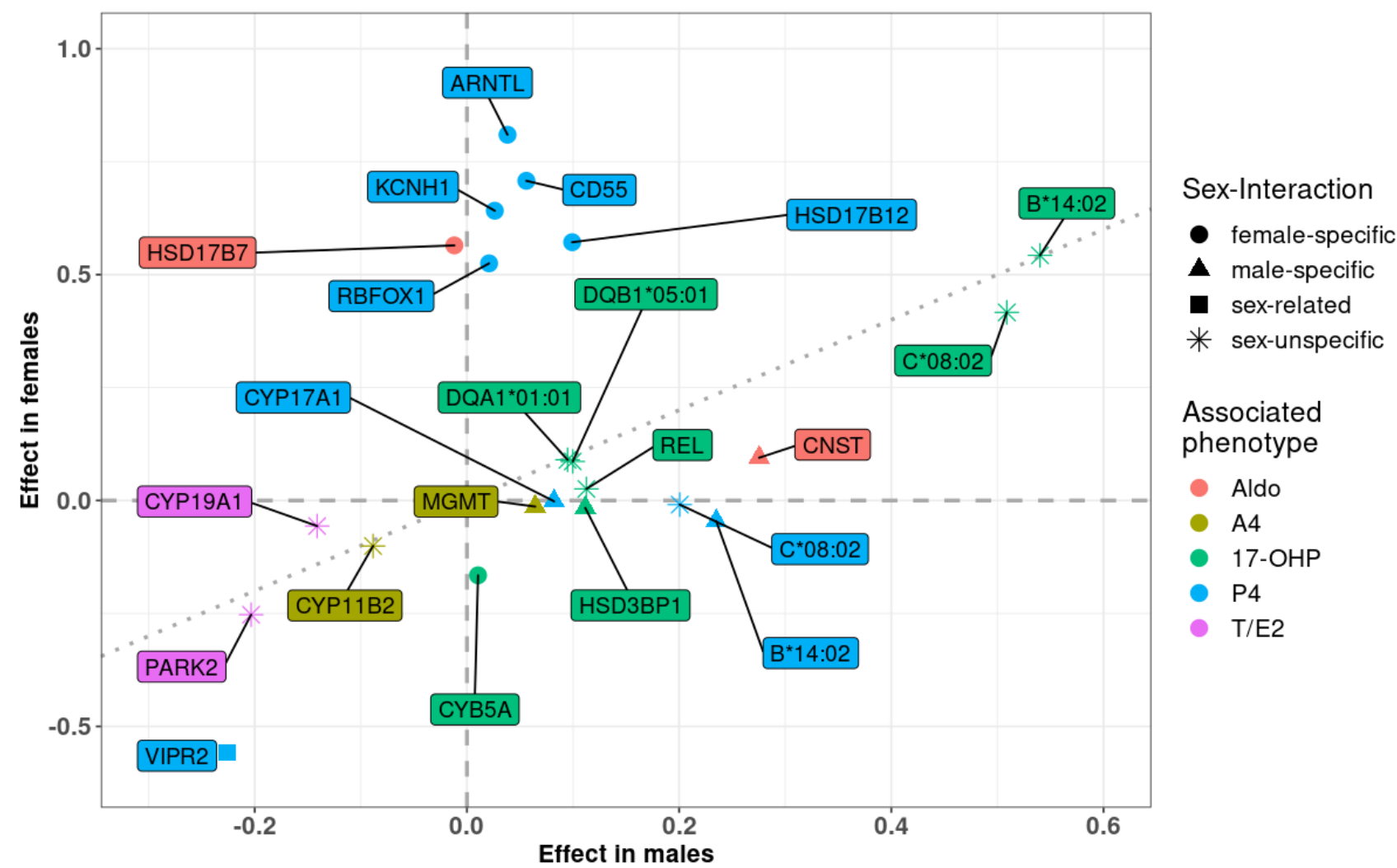

Figure 3. Scatter plot of sex-stratified effect estimates. Types of sex interactions are marked by shape (circle: female-specific; triangle: male-specific; square: sex-related; asterisk: no genetic sex interaction); and loci are colored by associated phenotypes. P4, progesterone; 17-OHP, hydroxyprogesterone; A4, androstenedione; Aldo, aldosterone; T/E2, ratio of testosterone and estradiol. 


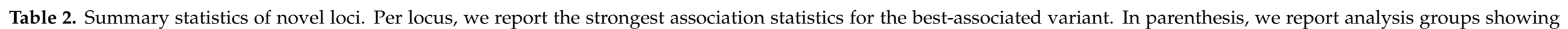

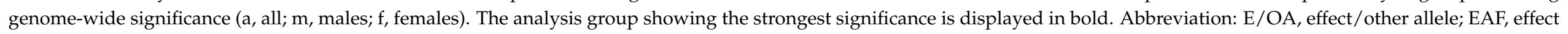

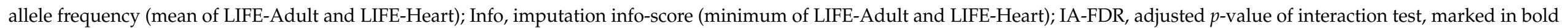
if significant. See supplementary material for justification of proposed candidate genes.

\begin{tabular}{|c|c|c|c|c|c|c|c|c|c|c|c|}
\hline Cytoband & Lead SNP & $\begin{array}{l}\text { Nearest Gene } \\
\quad(\mathbf{k b})\end{array}$ & $\begin{array}{c}\text { Candidate Gene } \\
(\mathbf{k b})\end{array}$ & E/OA & EAF & Info & $\begin{array}{l}\text { Associated } \\
\text { Phenotypes }\end{array}$ & $\beta(\mathrm{SE})$ & $p$ Value & $\mathbf{I}^{2}$ & IA-FDR \\
\hline $1 \mathrm{q} 32.2$ & rs138621610 & C1orf132 (0) & CD55 (445) & $\mathrm{A} / \mathrm{G}$ & 0.010 & 0.983 & $\mathrm{P} 4(\mathrm{a}, \mathbf{f})$ & $0.708(0.128)$ & $3.27 \times 10^{-08}$ & 0 & $4.97 \times 10^{-6}$ \\
\hline $7 q 36.3$ & rs2467806 & VIPR2 (0) & VIPR2 (0) & $\mathrm{C} / \mathrm{T}$ & 0.989 & 0.862 & $\mathrm{P} 4(\mathrm{a}, \mathrm{m}, \mathrm{f})$ & $-0.373(0.068)$ & $3.85 \times 10^{-08}$ & 0.892 & $1.87 \times 10^{-2}$ \\
\hline $1 \mathrm{p} 12$ & rs947130 & HSD3BP1 (0.31) & HSD3B1 (33) & $\mathrm{C} / \mathrm{T}$ & 0.731 & 0.922 & $17-\mathrm{OHP}(\mathrm{a}, \mathbf{m})$ & $0.112(0.017)$ & $1.03 \times 10^{-10}$ & 0 & $5.14 \times 10^{-4}$ \\
\hline $2 \mathrm{p} 15$ & rs17014577 & FAM161A (0) & REL (913) & $\mathrm{C} / \mathrm{T}$ & 0.143 & 0.991 & $17-\mathrm{OHP}(\mathrm{a}, \mathbf{m})$ & $0.113(0.021)$ & $4.49 \times 10^{-08}$ & 0 & $7.81 \times 10^{-2}$ \\
\hline $18 \mathrm{q} 22.3$ & rs1430542 & RN7SL401P (64) & CYB5A (442) & $\mathrm{C} / \mathrm{T}$ & 0.724 & 0.924 & $17-\mathrm{OHP}(\mathrm{a}, \mathbf{f})$ & $-0.166(0.028)$ & $6.21 \times 10^{-09}$ & 0 & $8.21 \times 10^{-7}$ \\
\hline $10 \mathrm{q} 26.3$ & rs11311009 & MGMT (0) & MGMT (0) & $\mathrm{C} / \mathrm{CT}$ & 0.419 & 0.980 & $\mathrm{~A} 4(\mathrm{a}, \mathbf{m})$ & $0.064(0.012)$ & $3.78 \times 10^{-08}$ & 0.367 & $7.06 \times 10^{-4}$ \\
\hline $14 \mathrm{q} 31.2$ & rs117866409 & Gene desert & CNST (trans-eQTL) & $\mathrm{C} / \mathrm{G}$ & 0.040 & 0.919 & Aldo $(a, \mathbf{m})$ & $0.275(0.050)$ & $3.42 \times 10^{-08}$ & 0.716 & $2.81 \times 10^{-2}$ \\
\hline $6 q 26$ & rs73013706 & PACRG (0) & PARK2 (20) & $\mathrm{G} / \mathrm{A}$ & 0.020 & 0.925 & $\mathrm{~T} / \mathrm{E} 2(\mathbf{a}, \mathrm{m}, \mathrm{f})$ & $-0.374(0.068)$ & $4.42 \times 10^{-08}$ & 0 & $7.07 \times 10^{-1}$ \\
\hline $15 q 21.2$ & rs727479 & CYP19A1 (0) & CYP19A1 (0) & $\mathrm{A} / \mathrm{C}$ & 0.659 & 0.999 & $\mathrm{~T} / \mathrm{E} 2(\mathrm{a}, \mathbf{m})$ & $-0.141(0.015)$ & $4.49 \times 10^{-21}$ & 0.814 & $5.44 \times 10^{-2}$ \\
\hline
\end{tabular}




\subsection{Fine-Mapping of the HLA Region}

The hormone 17-OHP was associated with multiple variants at the MHC region (872 SNPs with $p<1 \times 10^{-6}$ ), and the other four traits were all associated on a nominal level, e.g., 716 of the 872 SNPs were associated with P4 in males $(p<0.05)$. Therefore, we tested whether the human leukocyte antigen (HLA) subtypes associate with our steroid hormones. HLA subtypes were estimated from imputed genotypes, and associations were calculated using an allele dosage model (see Methods).

We derived 324 HLA-subtypes in LIFE-Adult and LIFE-Heart. After FDR correction, we detected significant associations for four of them: HLA-C* $08^{*} 02$, HLA-B ${ }^{*} 14^{*} 02$, HLADQA1 ${ }^{*} 01^{*} 01$, and HLA-DQB1*05*01 (see Tables 3 and S6 and Figure 4). The first two, HLA-C ${ }^{*} 08^{*} 02$ and HLA-B* $14^{*} 02$, are associated with $17-\mathrm{OHP}$ in a sex-unspecific way $\left(q_{I A}=0.722, q_{I A}=0.985\right.$, respectively). In addition, they were associated with P4 in males, but not in females or the combined setting. The effect difference was only significant for HLA-B ${ }^{*} 14^{*} 02\left(q_{I A}=0.0254\right)$, suggesting that this subtype had a male-specific effect on P4, but not on 17-OHP. HLA-C $\mathrm{C}^{*} 08^{*} 02$ and HLA-B ${ }^{*} 14^{*} 02$ are in high $\mathrm{LD}\left(\mathrm{r}^{2}=0.972\right.$ in our data, correlation of estimated subtype allele dosages). We contrasted this observation to measured haplotype frequencies from Wilson et al. [37], where the asymmetric LD (aLD) between HLA-B and $-C$ was estimated as 0.843 (for HLA-C conditioned on HLA-B; 0.650 for HLA-B conditioned on HLA-C). HLA-B* $14^{*} 02$ might be the more plausible candidate here, since it has been linked to CYP21A1 mutations [38,39].
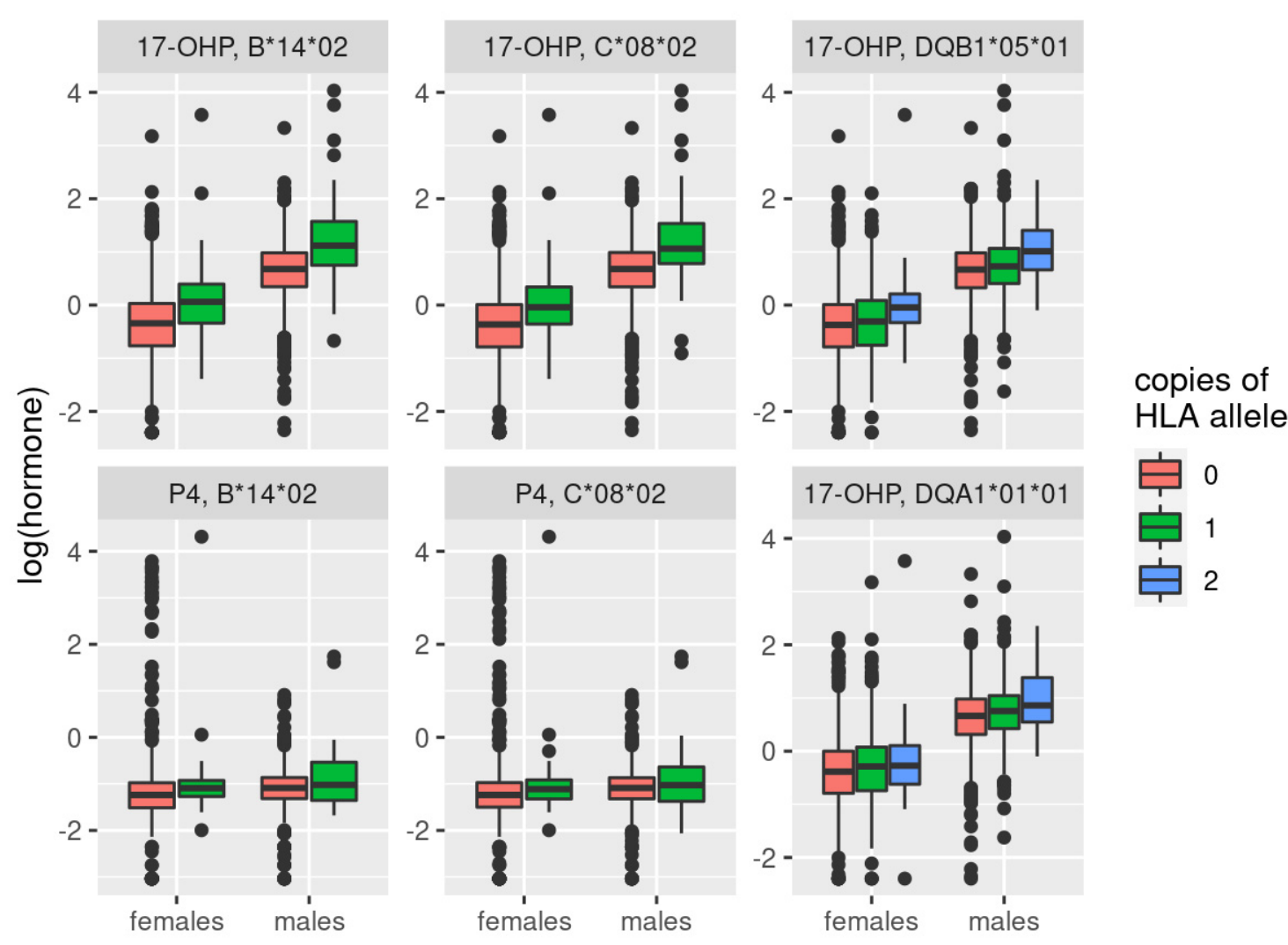

Figure 4. Boxplot of hormone levels for significant associations of HLA subtypes with either 17-OHP or P4. There was only a single male and female sample that had two copies of $C^{*} 08^{*} 02$ and $B^{*} 14^{*} 02$. For this plot, they were assigned to the group carrying one copy. Data of LIFE-Adult and LIFE-Heart were pooled for this plot, while analyses were performed with a fixed-effect meta-model. 
Table 3. Results from meta-analyses of the HLA subtypes on 17-OHP and P4. Significant associations are marked in bold. Allele dose associations were calculated in each study and then combined (fixed-effect meta-model). Further statistics are given in Table S6.

\begin{tabular}{|c|c|c|c|c|c|c|c|c|}
\hline \multirow{2}{*}{ HLA Subtype } & \multirow{2}{*}{ Phenotype } & \multicolumn{2}{|r|}{ All } & \multicolumn{2}{|c|}{ Males } & \multicolumn{2}{|c|}{ Females } & \multirow{2}{*}{ IA FDR } \\
\hline & & B & $p$ Value & $\beta$ & $p$ Value & $\beta$ & $p$ Value & \\
\hline \multirow{2}{*}{$\mathrm{B}^{*} 14^{*} 02$} & 17-OHP & 0.543 & $6.18 \times 10^{-20}$ & 0.540 & $8.96 \times 10^{-15}$ & 0.543 & $3.57 \times 10^{-7}$ & $9.85 \times 10^{-1}$ \\
\hline & $\mathrm{P} 4$ & 0.090 & $1.54 \times 10^{-01}$ & 0.235 & $1.83 \times 10^{-05}$ & -0.046 & $6.78 \times 10^{-1}$ & $2.54 \times 10^{-2}$ \\
\hline \multirow{2}{*}{$C^{*} 08^{*} 02$} & 17-OHP & 0.480 & $1.12 \times 10^{-20}$ & 0.509 & $2.29 \times 10^{-18}$ & 0.416 & $1.63 \times 10^{-5}$ & $7.22 \times 10^{-1}$ \\
\hline & $\mathrm{P} 4$ & 0.094 & $7.86 \times 10^{-02}$ & 0.201 & $1.17 \times 10^{-05}$ & -0.009 & $9.24 \times 10^{-1}$ & $4.88 \times 10^{-2}$ \\
\hline DQA1*01*01 & 17-OHP & 0.092 & $5.09 \times 10^{-06}$ & 0.095 & $3.33 \times 10^{-05}$ & 0.090 & $1.86 \times 10^{-2}$ & $9.85 \times 10^{-1}$ \\
\hline DQB1*05*01 & 17-OHP & 0.095 & $1.37 \times 10^{-05}$ & 0.100 & $5.30 \times 10^{-05}$ & 0.086 & $3.66 \times 10^{-2}$ & $9.85 \times 10^{-1}$ \\
\hline
\end{tabular}

The other two subtypes (HLA-DQA $1 * 01 * 01$ and HLA-DQB ${ }^{*} 05^{*} 0$ ) were only associated with 17-OHP in a sex-unspecific way ( $\mathrm{q}_{\mathrm{IA}}=0.985, \mathrm{q}_{\mathrm{IA}}=0.985$, respectively), and are also in high $\mathrm{LD}$ with each other $\left(\mathrm{r}^{2}=0.812\right.$ in our data, $\mathrm{aLD}=0.819$ from [37]). They are only in medium LD with HLA-B and -C (aLD of 0.32 and 0.33 , respectively), suggesting a secondary hit next to CYP21A2. Both HLA-DQA1 and HLA-DQB1 have been linked to steroid-sensitive nephrotic syndrome [40], and our observed association might provide a missing link between the HLA locus and this syndrome.

\subsection{Mendelian Randomization}

We tested for causal effects of our hormones on obesity-related traits (BMI, WHR) and CAD. Regarding obesity, we also checked for reverse causality and mediation effects on the hormone-CAD link (see Methods). Instruments and summary statistics for BMI, WHR, and CAD were retrieved from the literature [1,13], and the causal estimates for obesity on CAD were taken from [20].

\subsubsection{Causal Influence of Steroid Hormones on Obesity-Related Traits}

First, we tested for the causal effects of steroid hormones on BMI and WHR, stratified by sex. As instruments, we only used SNPs at loci with biologically plausible genes, e.g., coding for enzymes of the steroid biosynthesis pathway (max dist. $250 \mathrm{~kb}$ ). There were 13 pairs of hormones and obesity-related traits showing significant causal relationships, of which 12 survived multiple testing corrections (see Table 4, columns " $\alpha$ " and " $p(\alpha)$ " for significant links, and Table S7 for all tested combinations). These comprised five of the nine analyzed hormones (17-OHP, DHEA-S, E2, T, and T/E2), predominantly linked to WHR. For 17-OHP and DHEA-S, instruments for both sexes were available, while the other hormones had only instruments for one of the sexes. For DHEA-S and BMI, we detected sex-related causal effects, with stronger effects in males ( $\left.\mathrm{p}_{\mathrm{IA}}=0.043\right)$. The sex-specific effect difference of 17-OHP on WHR did not reach significance ( $\left.\mathrm{p}_{\mathrm{IA}}=0.055\right)$.

In an explorative approach, we tested if the results could be replicated using more but weaker SNPs, e.g., considering loci of suggestive significance $\left(p<1 \times 10^{-6}\right)$. We repeated the analyses for all combinations and detected four significant links: E2 on WHR in the combined setting, and, in males, T/E2 on WHR in the combined setting, and 17-OHP on WHR in females. We also repeated the interaction test as, now, instruments were available for both sexes, and found the causal effect of E2 on WHR to be male-specific $\left(\mathrm{p}_{\mathrm{IA}}=1.92 \times 10^{-7}\right)$.

We also tested if HLA subtypes could be used as instruments. Here, we considered only $17-\mathrm{OHP}$ and used only HLA-B* $14^{*} 02$ and HLA-DQA $1^{*} 01^{*} 01$ so as not to bias the analysis with the correlated instruments. HLA effects on obesity-related traits were estimated in the LIFE studies as summary statistics for HLA associations were not publicly available. We detected a nominally significant causal effect in all three settings on WHR but not BMI, and the interaction test revealed a sex-related effect on WHR, with stronger effects in females ( $\mathrm{p}_{\mathrm{IA}}=7.42 \times 10^{-3}$, see also Table S8). 
Table 4. Results of Mendelian randomization and mediation analyses of steroid hormones on CAD via obesity-related traits. First, the causal effects of the steroid hormones on the obesity-related mediators are provided (" $\alpha$ "). Then, the causal effects of the hormones on CAD are provided (" $\tau$ "). The indirect effect ("indir") is the product of $\alpha$ and the causal effect of the obesity-related mediator on CAD taken from Zhang et al. [20]. Finally, the direct effect of the steroid hormone on CAD is calculated as the difference between $\tau$ and the indirect effect ("dir"). Significant causal effects are displayed in bold.

\begin{tabular}{|c|c|c|c|c|c|c|c|c|c|c|}
\hline Exposure & Mediator & Set & $\alpha$ & $p(\alpha)$ & $\tau$ & $p(\tau)$ & indir & $p$ (indir) & dir & $p$ (dir) \\
\hline 17-OHP & BMI & a & 0.059 & $1.24 \times 10^{-05}$ & -0.108 & $1.06 \times 10^{-02}$ & 0.010 & $5.97 \times 10^{-03}$ & -0.118 & $5.30 \times 10^{-03}$ \\
\hline 17-OHP & WHR & a & -0.063 & $8.98 \times 10^{-06}$ & -0.108 & $1.06 \times 10^{-02}$ & -0.013 & $1.24 \times 10^{-02}$ & -0.095 & $2.60 \times 10^{-02}$ \\
\hline 17-OHP & WHR & $\mathrm{f}$ & 0.085 & $1.16 \times 10^{-07}$ & -0.095 & $7.79 \times 10^{-03}$ & 0.018 & $8.58 \times 10^{-03}$ & -0.113 & $1.93 \times 10^{-03}$ \\
\hline DHEAS & BMI & a & 0.081 & $7.97 \times 10^{-08}$ & 0.041 & $3.72 \times 10^{-01}$ & 0.014 & $3.14 \times 10^{-03}$ & 0.027 & $5.61 \times 10^{-01}$ \\
\hline DHEAS & BMI & $\mathrm{m}$ & 0.106 & $7.61 \times 10^{-07}$ & 0.066 & $1.43 \times 10^{-01}$ & 0.018 & $4.01 \times 10^{-03}$ & 0.047 & $2.96 \times 10^{-01}$ \\
\hline DHEAS & BMI & $\mathrm{f}$ & 0.051 & $2.36 \times 10^{-03}$ & 0.029 & $4.60 \times 10^{-01}$ & 0.009 & $2.11 \times 10^{-02}$ & 0.020 & $6.07 \times 10^{-01}$ \\
\hline DHEAS & WHR & a & 0.041 & $8.75 \times 10^{-03}$ & 0.041 & $3.72 \times 10^{-01}$ & 0.009 & $4.75 \times 10^{-02}$ & 0.032 & $4.83 \times 10^{-01}$ \\
\hline E2 & WHR & a & -0.150 & $1.13 \times 10^{-11}$ & 0.021 & $7.60 \times 10^{-01}$ & -0.031 & $5.70 \times 10^{-03}$ & 0.052 & $4.53 \times 10^{-01}$ \\
\hline E2 & WHR & $\mathrm{m}$ & -0.213 & $2.56 \times 10^{-12}$ & 0.020 & $7.60 \times 10^{-01}$ & -0.044 & $5.47 \times 10^{-03}$ & 0.064 & $3.33 \times 10^{-01}$ \\
\hline $\mathrm{T}$ & WHR & a & -0.136 & $1.78 \times 10^{-05}$ & -0.203 & $2.76 \times 10^{-02}$ & -0.028 & $1.34 \times 10^{-02}$ & -0.175 & $6.01 \times 10^{-02}$ \\
\hline $\mathrm{T} / \mathrm{E} 2$ & WHR & a & 0.112 & $1.13 \times 10^{-11}$ & -0.016 & $7.60 \times 10^{-01}$ & 0.023 & $5.70 \times 10^{-03}$ & -0.039 & $4.53 \times 10^{-01}$ \\
\hline $\mathrm{T} / \mathrm{E} 2$ & WHR & $\mathrm{m}$ & 0.139 & $2.56 \times 10^{-12}$ & -0.013 & $7.60 \times 10^{-01}$ & 0.029 & $5.47 \times 10^{-03}$ & -0.042 & $3.33 \times 10^{-01}$ \\
\hline
\end{tabular}

\subsubsection{Test for Reversed Causality of Obesity-Related Traits on Steroid Hormones}

To assess whether there is reverse causality of obesity-related traits on steroid hormone levels, we tested these causal directions using genome-wide significant instruments from Pulit et al. [13], allowing only one SNP per cytoband. We observed eight significant causal relationships, including BMI on DHEA-S and WHR on E2 and T, but none of them withstood multiple testing correction (see Table S7). In a sensitivity approach using only strong instruments, i.e., SNPs explaining at least $0.1 \%$ of the variance of the considered obesity-related trait, we found no significant causal relationships.

\subsubsection{Causal Effect of Steroid Hormones on CAD and Mediation via Obesity Traits}

Finally, we estimated the total causal effects of the steroid hormones on CAD, using the same instruments as described above and the summary statistics for CAD taken from [1]. To assess the mediation effect of obesity-related traits, we also estimated the indirect effect as the product of the effect sizes of steroid hormone on the obesity-related trait and of the latter on CAD (taken from [20]). The direct effect can then be calculated as the difference between the total and indirect effects (see Methods).

There were two significant total causal links: a negative effect of 17-OHP on CAD in both the combined setting and in females (see Table 4, columns " $\tau$ " and "p $p(\tau)$ " and Figure 5). The effect was sex-unspecific ( $\left.\mathrm{p}_{\mathrm{IA}}=0.750\right)$. In the sensitivity analysis, the effect in females was still nominally significant, but did not survive multiple testing correction (see Table S9).

Mediation tests were restricted to the 12 causally connected pairs of steroid hormones and obesity-related traits. All related hormones had a significant indirect effect on CAD (see Table 4 columns "indir" and "p(indir)"), but only for 17-OHP, we observed significant direct effects (see Table 4 columns "dir" and " $p($ dir)"). Thus, all other causal relationships of hormones on CAD were mediated by obesity-related traits. As the causal effects of BMI and WHR on CAD are both positive, the directions of the indirect effect were inherited from the causal relationships of the steroid hormones on the respective obesity-related traits, e.g., a positive effect of DHEA-S and T/E2 on CAD, but negative effects of E2 and T on CAD.

Since 17-OHP was the only hormone with both, direct and indirect effects on CAD, we aimed at replicating our causal estimates considering the identified associations with HLA subtypes. This analysis confirmed that $17-\mathrm{OHP}$ causally affects CAD in a sex-unspecific way (interaction $p$-values: $p=0.291$ for the direct effect, $p=0.271$ for the total effect, $p=0.149$ 
for the indirect effect via WHR). The mediation via WHR could also be replicated. All results are summarized in Table S10.
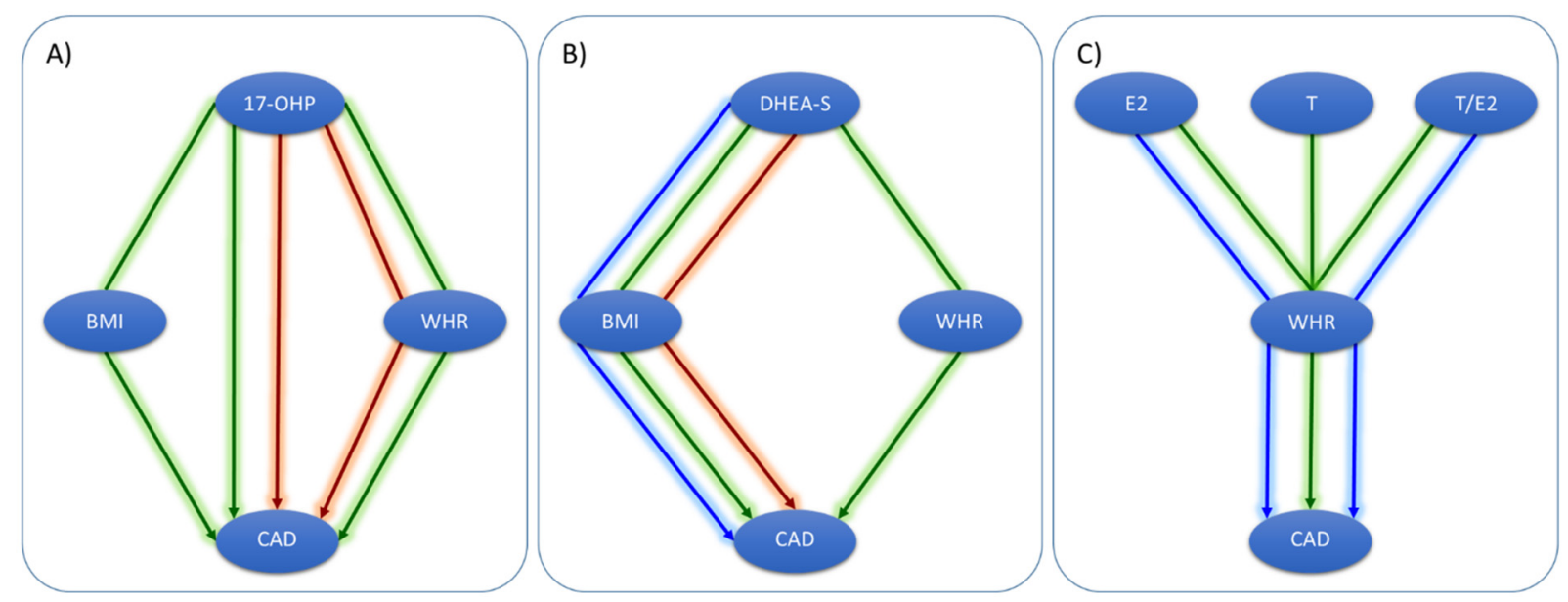

Figure 5. Detected causal networks of direct and indirect effects. Arrows indicate the analysis setting: green = combined; blue = males; red = females. $(\mathrm{A})$ For 17-OHP, we detected direct and indirect effects on CAD, mediated by both BMI and WHR. (B) For DHEAS, we detected only indirect effects on CAD, mediated by both BMI and WHR. (C) For E2, T, and T/E2, we found indirect effects on CAD via WHR.

\section{Discussion}

In the present study, we analyzed causal relationships of steroid hormones, obesityrelated traits, and CAD. This was performed in a sex-stratified manner in order to contribute to the explanation of the sexual dimorphisms of these traits.

To obtain strong and valid instruments for MR analyses, we first performed sexstratified GWAMAs of four steroid hormones: progesterone (P4), hydroxyprogesterone (17-OHP), androstenedione (A4), and aldosterone. This is an extension of our previous work [22], in which only data of one study was available for these hormones. As a novel trait of interest, we analyzed the testosterone to estradiol (T/E2) ratio. This parameter of the disturbance of the normal physiological balance of these two hormones is discussed in relation to cardiovascular disease risk [41,42]. While we successfully replicated 7 known loci, we also discovered 11 novel loci associated with these traits, of which 9 showed sex-specific effects after stringent FDR correction.

Three of these novel loci are directly linked to steroid hormone biosynthesis, namely HSD3B1/B2 (associated with 17-OHP in males), HSD17B7 (associated with aldosterone in females), and CYP19A1 (associated with T/E2 in males but without differences in effect size compared to females). The HSD3B1/B2 gene codes for $3 \beta$-hydroxysteroid dehydrogenases (two isomerases, B1 and B2) are required for the production of all biologically active steroid hormones [43]. The enzyme 17 $\beta$-hydroxysteroid dehydrogenase type B7 (HSD17B7) is responsible for the transformation of estrone to estradiol [44], which might explain the observed female-specific effect. The link to aldosterone remains unclear so far. The hit at the CYP19A1 gene has been previously reported for E2 [45] and T [35], but not for the ratio yet. The gene codes for the aromatase catalyze the metabolic step from T to E2.

We were able to replicate the associations at 6 p21.32, 6p21.33, and 6p22.1 for 17-OHP. In our previous work [22], we did not use any fine-mapping techniques to characterize this MHC locus in more detail. Here, we used estimated HLA subtypes as an explanatory variable in a regression model for the first time and identified two of them strongly associated with 17-OHP and P4 levels, namely, HLA-C*08 and HLA-B*14, explaining the previously observed association within the MHC region. They are in LD, and HLA-B ${ }^{*} 14$ might be the plausible candidate here since it has been linked to CYP21A1 mutations $[38,39]$ and congenital adrenal hyperplasia [46]. For our study, we excluded all participants suspected to have this autosomal recessive disorder. The observed association might be a 
sub-clinical sign for a disease allele carrier. Interestingly, there was a sex-specific effect on P4, but not on 17-OHP.

In our MR analyses, we used as instruments our previously published data for cortisol, DHEA-S, T and E2 [22], and our new summary statistics for 17-OHP, P4, A4, aldosterone, and T/E2. For BMI, WHR and CAD, we used publicly available summary statistics $[1,13]$. We detected a sex-related positive causal effect of DHEA-S on BMI, with stronger effects in females. DHEA and its sulfated ester DHEA-S are the major steroid pro-hormones in human circulation that decline with age [47]. They are transported to adipocytes [48], where DHEA is transformed to A4, which can activate the expression of androgen receptor genes [49]. Some studies have shown that DHEA reduces body fat mass in men but not women [50,51], while other trials focusing on long-term effects found no significant changes [52]. Since MR estimates the life-long causal effects of a small variation of a risk factor (due to genetics) on an outcome, its results are not necessarily comparable to clinical trials typically designed to demonstrate a short-term impact by large variations of the risk factor. As instruments for MR, we used SNPs near or within CYP3A4 and SULT2A1, both catalyzing the reaction of DHEA to another metabolite, 16 $\alpha$-OH-DHEA and DHEA-S, respectively. In our previous work, we found sulfonation and de-sulfonation genetically regulated in females, but not males [22]. The positive effect direction we observed for DHEA-S was discordant to the above-mentioned studies regarding DHEA. Further studies regarding these sex-specific regulations of DHEA-S and their causal effect directions are required for functional validation of this mechanism.

For 17-OHP, we detected sex-unspecific causal effects on BMI, WHR, and CAD. Both direct and indirect effects on $C A D$, mediated via obesity-related traits were observed. The hormone was proposed as an independent predictor of WHR [53], and abdominal obesity was assumed to be associated with decreased activity of adrenal 21-hydroxylase, which is coded by CYP21A1 in the HLA region. This is in line with our findings. In women with polycystic ovary syndrome, a positive correlation between 17-OHP and epicardial fat thickness was reported [54]. Epicardial fat thickness is related to subclinical atherosclerosis and visceral fat changes. We detected the negative causal effects of 17-OHP on CAD, both in the main analyses using SNPs and the summary statistics from van der Harst [1] and in the sensitivity analyses using HLA subtypes and only the data of our own studies. Supporting our finding, in a male rabbit model, the group on high-dose 17-OHP was found to be associated with less aortic plaques than controls, after controlling for cholesterol and triglyceride levels [55]. In summary, the causal links of 17-OHP to WHR and CAD are plausible.

Finally, we found the causal effects of E2, T, and T/E2 on WHR in both the combined setting and males. For the female subgroup, estimates could not be calculated since there were either no strong instruments for females (T, T/E2) or the statistics of the outcome could not be matched to the available instrument (E2). Hence, the sex-specificity for these links could not be tested. The effects of E2 and T alone were negative, while the hormone ratio had a positive causal effect on WHR. In a study of young women, both E2 and T were negatively correlated with WHR, but there was a significant $\mathrm{T} \times \mathrm{E} 2$ interaction on WHR [56]. Hence, our results are in line with previous findings, but further GWAS on T, E2, and their ratio is required to detect further strong SNPs to be used as instruments in MR.

This study was limited by the small number of instruments for the steroid hormones, which lowers the power of Mendelian randomization. However, for all hormones, instruments in or nearby genes with direct influence on the steroid hormone synthesis pathway were available, strengthening the assumption that the variants affect the analyzed outcomes via the respective hormone. A second limitation is that the summary statistics for CAD were only available for the combined setting. According to the latest CAD GWAMA [57], there are only nine sex-specific CAD loci, suggesting that the combined effects could be used for the sex-stratified analyses as well. Finally, our MR methods provide causality estimates in a statistical sense, requiring validations in experiments or randomized trials. 
In conclusion, we identified 11 novel genetic loci of steroid hormone levels with pronounced sex effects. In a fine-mapping approach of the MHC region, we found two HLA subtypes significantly associated with 17-OHP and P4. Based on these loci, we discovered the sex-specific causal networks of steroid hormones, obesity-related traits, and CAD.

\section{Materials and Methods}

\subsection{Cohort Description}

Two studies of the Leipzig Research Centre for Civilization Diseases (LIFE) were analyzed: LIFE-Adult is a population-based cohort of citizens of Leipzig, Germany $(n=10,000)$ [24]. Recruitment took place from 2011 to 2016. Participants were phenotyped in detail with respect to common civilization diseases such as subclinical atherosclerosis, metabolic diseases, and cognitive function.

LIFE-Heart is a cohort of patients with suspected or confirmed coronary artery disease or myocardial infarction [23]. Patients were recruited at the Heart Center Leipzig, Germany, and all underwent coronary angiography. In the subset of patients with suspected CAD, other atherosclerotic traits were also assessed, including plaques of carotid vessels and ankle-brachial-index.

Both LIFE studies meet the ethical standards of the Declaration of Helsinki. They are approved by the Ethics Committee of the Medical Faculty of the University of Leipzig, Germany (Adult: Reg. No. 263-2009-14122009, Heart: Reg. No. 276-2005). Written informed consent, including agreement to genetic analyses was obtained from all participants.

\subsection{Measurement of Steroid Hormones, Obesity Traits, and CAD}

In LIFE-Adult, levels of the four steroid hormones-progesterone (P4), hydroxyprogesterone (17-OHP), androstenedione (A4), and aldosterone-were measured by liquid chromatography-tandem mass spectrometry (LC-MSMS) [58], while testosterone (T) and estradiol (E2) were measured by an electrochemiluminescence immunoassay (ECLIA; Roche Cobas). In LIFE-Heart, all six steroid hormones were measured by LC-MSMS.

Samples were excluded from hormone analyses if the participant was on steroid medication (ATC codes starting with "G03" or "H02AB") or if quality control of the steroid profile suggested a mix-up of samples, or underlying diseases, e.g., hyperandrogenism, hypogonadism, adrenal insufficiency, congenital adrenal hyperplasia, or polycystic ovary syndrome.

In both studies, participants were measured for height, weight, and waist and hip girths. Based on these characteristics, BMI and WHR were calculated as obesity-related traits. All LIFE-Heart patients received diagnostic coronary angiography, and CAD was defined as at least one stenosis of $\geq 50 \%$ of any major coronary vessel. Both, anthropometric and CAD data were used in MR sensitivity analyses using HLA subtypes as instruments.

\subsection{Genotyping, Imputation, and HLA Subtype Estimation}

Both LIFE studies were genotyped using the Affymetrix Axiom SNP-array technology [59] (LIFE-Adult: CEU1 array, LIFE-Heart: CEU1 or CADLIFE array (customized CEU1 array containing additional SNPs from CAD loci)). Genotype calling was performed for each study with Affymetrix Power Tools (v1.20.6 for LIFE-Adult CEU1; v1.17.0 for LIFEHeart CADLIFE; v1.16.1 for LIFE-Heart CEU1), following best practice steps for quality control. These steps comprised sample filters for signal contrast and sample-wise call rate, and SNP filters regarding platform specific cluster criteria. The datasets of LIFE-Heart typed with different array platforms were merged after calling (intersection of SNPs).

Samples with XY irregularities, including sex mismatches or cryptic relatedness, and genetic outliers ( $>6 \mathrm{SD}$ of genetic principal components) were excluded. Further, variants with a call rate less than 0.97, Hardy-Weinberg equilibrium $p<1 \times 10^{-6}$, and minor allele frequency $(\mathrm{MAF})<0.01$ were removed before imputation. Imputation was performed using the 1000 Genomes Project Phase 3 European reference panel [25] with 
IMPUTE2 [60]. In summary, 7669 and 5700 samples were genotyped in LIFE-Adult and LIFE-Heart, respectively (7660 and 5688 samples for chromosome $X$ ).

To estimate the HLA subtypes, we selected all SNPs of the MHC region on chromosome $6(25,392,021-33,392,022 \mathrm{Mb}$ according to hg19, a long-range LD region) that could be matched to the Axiom HLA reference set [61]. The best-guess genotype was defined with the threshold of genotype probability $>0.9$, and SNPs with more than $3 \%$ missing genotype calls were excluded. Then, HLA subtypes were imputed using the Axiom HLA Analyses Tool [61,62]. A probability score was given for each sample and allele, and to filter for good quality, the combined probability was used (product of two probability scores per sample, threshold $\geq 0.7)$. In addition, we excluded HLA subtypes that were rare $(<1 \%$ in each study). For every HLA subtype and sample, we estimated the dosage of each allele ranging from 0 to 2 .

\subsection{Statistical Analysis}

\subsubsection{GWAMA}

Single study GWAS. The four hormones (P4, 17-OHP, A4, and aldosterone) and the hormone ratio (T/E2) were log-transformed for all analyses to obtain normally distributed traits. We performed genome-wide association analysis for each study (GWAS) and phenotype in all samples (combined setting) and sex-stratified samples (male and female settings), with adjustment for age, log-transformed BMI, and sex in the combined setting. For analyses, we used the additive frequentist model with expected genotype counts as implemented in PLINK $2.0[63,64]$.

File QC. All SNPs were harmonized to the same effect allele and were filtered for minor allele frequency $(\mathrm{MAF})<1 \%$, imputation info score $<0.5$, and minor allele count (MAC) $\leq 6$. In addition, we checked for mismatching alleles or chromosomal position with respect to 1000 Genomes Phase 3 European reference [25] and excluded SNPs with a high deviation of study to reference allele frequency (absolute difference >0.2). Only SNPs in the intersection of both studies were meta-analyzed.

Meta analyses. For meta-analyses, single study results per phenotype and setting were combined using a fixed-effect model, assuming homogenous genetic effects across studies. We used $\mathrm{I}^{2}$ statistics to evaluate heterogeneity and filtered our results with $\mathrm{I}^{2} \geq 0.9$. Finally, we excluded SNPs with a minimum imputation info-score across studies of less than 0.8 . The genome-wide and suggestive significance levels were set to $\alpha_{\mathrm{gw}}=5 \times 10^{-8}$ and $\alpha_{\text {sug }}=5 \times 10^{-6}$, respectively.

Annotation. SNPs reaching at least suggestive significance for one of the phenotypes were annotated with nearby genes [65], eQTLs [66] in linkage disequilibrium (LD) $\mathrm{r}^{2}>0.3$, and known associated traits [67] in LD $\mathrm{r}^{2}>0.3$ using 1000 Genomes Phase 3 (European samples) [25] as the LD reference. We also used the genome-wide data to estimate the genetically regulated gene expression per tissue and tested for their association with our hormone levels (MetaXcan [68]).

\subsubsection{HLA Association}

We used linear regression models to test for associations of the dosage of HLA subtypes with hormone levels. The same models as described in the GWAMA section were analyzed. There were 108 HLA subtypes available in both studies for meta-analyses. Regression models were run in R v.3.6.0. We also tested BMI, WHR, and CAD for association with HLA subtypes. Here, we used linear regression for analyses of BMI and WHR and logistic regression for analysis of CAD, and adjusted for age, log-BMI (in the WHR analysis), and sex (in the combined analysis). CAD was only available in LIFE-Heart, while BMI and WHR were available in both LIFE cohorts.

To identify independent subtypes, we estimated pairwise correlations between subtype allele dosages (i.e., Pearson's correlation between HLA-B* $14^{*} 02$ and HLA-C $C^{*} 08^{*} 02$ ). In addition, we looked up asymmetric LD between HLA genes (e.g., HLA-B and HLA-C). While traditional LD estimates the correlation between bi-allelic loci, asymmetric LD cap- 
tures the asymmetry of multi-allelic loci [69]. We used haplotype frequencies from Wilson et al. [37], and the function compute.ALD() of the R package "asymLD" [69].

\subsubsection{Genetic Sex Interaction}

We tested the 16 lead SNPs reaching genome-wide significance in any setting and the six significant HLA subtypes associated with steroid hormone levels regarding sexspecific effects. This was done by comparing the effect sizes of males and females for the best-associated phenotype ( $t$-tests of $\beta$ estimates) [70]. To adjust for multiple testing of several SNPs per hormone, we performed hierarchical FDR correction [71]. The first level of correction was the number of SNPs per hormone; the second level was the analyzed hormones.

\subsubsection{Mendelian Randomization (MR)}

MR models. We investigated three possible causal links between steroid hormones, obesity-related traits, and CAD in a sex-specific manner. First, we tested for causal links between steroid hormones and obesity-related traits (BMI, WHR) in both directions. Then, we searched for causal links of steroid hormones on CAD and tested all significant links of steroid hormones and obesity-related traits for mediation effects on CAD by estimating direct and indirect effects (mediation MR). A graphical summary of this approach is given in Figure 1.

Data Source. As instruments for SH, we used SNPs associated with the analyzed hormones at biologically meaningful loci, e.g., genes coding for enzymes of the steroid hormone biosynthesis pathway. Statistics were obtained from the above-mentioned GWAMA and our previous work on cortisol, DHEAS, T, and E2 [22]. While sex-stratified summary statistics were available for BMI and WHR [13], this was not the case for CAD [1]. Thus, we used the combined effect estimates for all CAD analyses, i.e., we assumed no sex interactions of CAD associations. Since not all SNPs were available for all outcomes, we first used a liberal cut-off of $1 \times 10^{-6}$ to get a comprehensive SNP list, and then selected for each exposure-outcome combination the best-associated SNP per locus for which outcome statistics are available. For 17-OHP, we repeated the analyses using the associated HLA subtypes as instruments to replicate our respective causal findings. As for these subtypes, association statistics for BMI, WHR, and CAD were not available in the literature; we estimated them in our LIFE studies.

Key Assumptions. SNPs were assumed to satisfy the three MR assumptions for instrumental variables (IVs): (1) The IVs were, genome-wide, significantly associated with the exposure of interest. This was shown by our GWAMA results. (2) The IVs were uncorrelated with confounders of the relationship of exposure and outcome. This might be a concern for sex, since the SNPs are partly sex-specific or sex-related, and the outcomes display sexual dimorphisms. Therefore, we ran all MR analyses in a sex-stratified manner using only those SNPs as IVs that were significant in the respective strata. (3) The IVs correlated with the outcome exclusively by affecting the exposure levels (no direct SNP effect on the outcome). Some loci are known to be associated with CAD or obesity (e.g., CYP19A1). However, it is highly plausible that this condition holds because we only considered loci of the steroid hormone biosynthesis pathway, which should have a direct effect on hormones.

MR Analyses. For most exposures (i.e., hormone levels), only one genome-wide significant locus was available. Hence, only one instrument was available and we applied the ratio method, which estimates the causal effect as the ratio of the SNP effect on the outcome by the SNP effect on the exposure [21]. The standard error was obtained by the first term of the delta method [21]. In the case of multiple independent instruments, we used the inverse variance weighted method to combine the single ratios [72]. To adjust for multiple testing, we performed hierarchical FDR correction per exposure [73]. First, FDR was calculated for each exposure separately. Second, FDR was determined over the best-causally related outcome per exposure. We then applied a significance threshold of 
$\alpha=0.05 \times \mathrm{k} / \mathrm{n}$ on the first level, with $\mathrm{k} / \mathrm{n}$ being the ratio of significance to all exposures at the second level.

For mediation analyses, we used the total causal estimates $\alpha$ ( $\mathrm{SH} \rightarrow$ obesity-related trait), $\tau$ (SH $\rightarrow \mathrm{CAD}$ ), and $\beta$ (obesity-related trait $\rightarrow \mathrm{CAD}$ ). While $\alpha$ and $\tau$ were calculated as described above, the causal effects of BMI and WHR on CAD were taken from [20] (Table 1). The OR and confidence intervals reported there were then transformed to effect sizes through dividing by 1.81 according to [74]. The indirect effect was estimated as the product of $\alpha$ and $\beta$. This product was compared with the direct effect $\tau$ by formal $t$-statistics of the differences:

$$
\begin{gathered}
\hat{\beta}_{\text {indir }}(\mathrm{SH} \rightarrow \mathrm{CAD})=\alpha \times \beta, \\
\mathrm{SE}\left(\hat{\beta}_{\text {indir }}\right)=\sqrt{\alpha^{2} \times \mathrm{SE}(\beta)+\beta^{2} \times \mathrm{SE}(\alpha)} \\
\hat{\beta}_{\text {dir }}(\mathrm{SH} \rightarrow \mathrm{CAD})=\tau-\hat{\beta}_{\text {indir }}(\mathrm{SH} \rightarrow \mathrm{CAD}), \\
\mathrm{SE}\left(\hat{\beta}_{\text {dir }}\right)=\sqrt{\mathrm{SE}(\tau)^{2}+\mathrm{SE}\left(\hat{\beta}_{\text {indir }}\right)^{2}}
\end{gathered}
$$

Supplementary Materials: The following data are available online at https://www.mdpi.com/ article/10.3390/metabo11110738/s1, Supplemental Tables S1-S10 and Supplemental Data of the GWAMA results.

Author Contributions: Conceptualization, J.P. and M.S.; methodology, J.P.; software, H.K., K.H. and P.A.; formal analysis, J.P.; investigation, J.P., R.Z., M.S., J.K. and U.C.; resources, M.L., U.C. and B.I.; data curation, K.H., H.K., P.A., J.K. and U.C.; writing-original draft preparation, J.P.; writingreview and editing, M.S. and H.K.; visualization, J.P.; supervision, M.S.; project administration, M.S.; funding acquisition, J.P. and M.S. All authors have read and agreed to the published version of the manuscript.

Funding: LIFE-Adult was funded by the Leipzig Research Center for Civilization Diseases (LIFE). LIFE was funded by means of the European Union, the European Regional Development Fund (ERDF, grant 713-24120) and by means of the Free State of Saxony within the framework of the excellence initiative (14505/2470). JP was funded by a grant from the Medical Faculty of Leipzig (HIMAG-108, SASHA). This work was supported by the German Federal Ministry of Education and Research (BMBF) within the framework of the e:Med research and funding concept (SYMPATH, grant \# 01ZX1906B). We acknowledge support from Leipzig University for Open Access Publishing.

Institutional Review Board Statement: The study was conducted according to the guidelines of the Declaration of Helsinki, and approved by the Ethics Committee of the Medical Faculty of the University Leipzig, Germany (Adult: Reg. No. 263-2009-14122009, Heart: Reg. No. 276-2005).

Informed Consent Statement: Written informed consent including agreement to genetic analyses, was obtained from all subjects involved in the studies.

Data Availability Statement: The data presented in this study are openly available in [Zenodo] at [doi.org/10.5281/zenodo.5644896].

Acknowledgments: We thank all study participants of the LIFE studies whose personal dedication and commitment have made this project possible. We thank Kerstin Wirkner for running the LIFE study center, and Sylvia Henger for data quality control. LIFE-Adult genotyping (round 3) was done at the Cologne Center for Genomics (CCG, University of Cologne, Peter Nürnberg and Mohammad R. Toliat). For genotype imputation, the computer infrastructure provided by ScaDS (Dresden/Leipzig Competence Center for Scalable Data Services and Solutions) at the Leipzig University Computing Center was used.

Conflicts of Interest: The authors declare no conflict of interest. 


\section{References}

1. van der Harst, P.; Verweij, N. Identification of 64 Novel Genetic Loci Provides an Expanded View on the Genetic Architecture of Coronary Artery Disease. Circ. Res. 2018, 122, 433-443. [CrossRef]

2. Loley, C.; Alver, M.; Assimes, T.L.; Bjonnes, A.; Goel, A.; Gustafsson, S.; Hernesniemi, J.; Hopewell, J.C.; Kanoni, S.; Kleber, M.E.; et al. No Association of Coronary Artery Disease with X-Chromosomal Variants in Comprehensive International Meta-Analysis. Sci. Rep. 2016, 6, 35278. [CrossRef]

3. Haast, R.A.M.; Gustafson, D.R.; Kiliaan, A.J. Sex differences in stroke. J. Cereb. Blood Flow Metab. 2012, 32, 2100-2107. [CrossRef] [PubMed]

4. Iorga, A.; Cunningham, C.M.; Moazeni, S.; Ruffenach, G.; Umar, S.; Eghbali, M. The protective role of estrogen and estrogen receptors in cardiovascular disease and the controversial use of estrogen therapy. Biol. Sex Differ. 2017, 8, 33. [CrossRef] [PubMed]

5. Di Giosia, P.; Giorgini, P.; Stamerra, C.A.; Petrarca, M.; Ferri, C.; Sahebkar, A. Gender Differences in Epidemiology, Pathophysiology, and Treatment of Hypertension. Curr. Atheroscler. Rep. 2018, 20, 13. [CrossRef]

6. Xu, X.; Gao, B.; Guan, Q.; Zhang, D.; Ye, X.; Zhou, L.; Tong, G.; Li, H.; Zhang, L.; Tian, J.; et al. Metabolomic profile for the early detection of coronary artery disease by using UPLC-QTOF/MS. J. Pharm. Biomed. Anal. 2016, 129, 34-42. [CrossRef] [PubMed]

7. Shufelt, C.; Bretsky, P.; Almeida, C.M.; Johnson, B.D.; Shaw, L.J.; Azziz, R.; Braunstein, G.D.; Pepine, C.J.; Bittner, V.; Vido, D.A.; et al. DHEA-S levels and cardiovascular disease mortality in postmenopausal women: Results from the National Institutes of Health—National Heart, Lung, and Blood Institute (NHLBI)-sponsored Women's Ischemia Syndrome Evaluation (WISE). J. Clin. Endocrinol. Metab. 2010, 95, 4985-4992. [CrossRef]

8. World Health Organization. Obesity-Preventing and Managing the Global Epidemic: Report on a WHO Consultation; World Health Organization: Geneva, Switzerland, 2000; ISBN 9789241208949.

9. Palmer, B.F.; Clegg, D.J. The sexual dimorphism of obesity. Mol. Cell. Endocrinol. 2015, 402, 113-119. [CrossRef]

10. Tchernof, A.; Brochu, D.; Maltais-Payette, I.; Mansour, M.F.; Marchand, G.B.; Carreau, A.-M.; Kapeluto, J. Androgens and the Regulation of Adiposity and Body Fat Distribution in Humans. Compr. Physiol. 2018, 8, 1253-1290. [CrossRef]

11. Andreacchi, A.T.; Griffith, L.E.; Guindon, G.E.; Mayhew, A.; Bassim, C.; Pigeyre, M.; Stranges, S.; Anderson, L.N. Body mass index, waist circumference, waist-to-hip ratio, and body fat in relation to health care use in the Canadian Longitudinal Study on Aging. Int. J. Obes. 2021, 45, 666-676. [CrossRef]

12. Mørkedal, B.; Romundstad, P.R.; Vatten, L.J. Informativeness of indices of blood pressure, obesity and serum lipids in relation to ischaemic heart disease mortality: The HUNT-II study. Eur. J. Epidemiol. 2011, 26, 457-461. [CrossRef]

13. Pulit, S.L.; Stoneman, C.; Morris, A.P.; Wood, A.R.; Glastonbury, C.A.; Tyrrell, J.; Yengo, L.; Ferreira, T.; Marouli, E.; Ji, Y.; et al. Meta-analysis of genome-wide association studies for body fat distribution in 694649 individuals of European ancestry. Hum. Mol. Genet. 2019, 28, 166-174. [CrossRef]

14. Zhang, H.; Sairam, M.R. Sex hormone imbalances and adipose tissue dysfunction impacting on metabolic syndrome; a paradigm for the discovery of novel adipokines. Horm. Mol. Biol. Clin. Investig. 2014, 17, 89-97. [CrossRef]

15. Even, S.E.L.; Dulak-Lis, M.G.; Touyz, R.M.; Nguyen Dinh Cat, A. Crosstalk between adipose tissue and blood vessels in cardiometabolic syndrome: Implication of steroid hormone receptors (MR/GR). Horm. Mol. Biol. Clin. Investig. 2014, 19, 89-101. [CrossRef]

16. Tchernof, A.; Mansour, M.F.; Pelletier, M.; Boulet, M.-M.; Nadeau, M.; Luu-The, V. Updated survey of the steroid-converting enzymes in human adipose tissues. J. Steroid Biochem. Mol. Biol. 2015, 147, 56-69. [CrossRef]

17. Campbell, K.L.; Foster-Schubert, K.E.; Makar, K.W.; Kratz, M.; Hagman, D.; Schur, E.A.; Habermann, N.; Horton, M.; Abbenhardt, C.; Kuan, L.-Y.; et al. Gene expression changes in adipose tissue with diet- and/or exercise-induced weight loss. Cancer Prev. Res. 2013, 6, 217-231. [CrossRef]

18. Gates, M.A.; Mekary, R.A.; Chiu, G.R.; Ding, E.L.; Wittert, G.A.; Araujo, A.B. Sex steroid hormone levels and body composition in men. J. Clin. Endocrinol. Metab. 2013, 98, 2442-2450. [CrossRef] [PubMed]

19. Gong, Y.; Xiao, H.; Li, C.; Bai, J.; Cheng, X.; Jin, M.; Sun, B.; Lu, Y.; Shao, Y.; Tian, H. Elevated t/e2 ratio is associated with an increased risk of cerebrovascular disease in elderly men. PLoS ONE 2013, 8, e61598. [CrossRef]

20. Zhang, X.; Lv, W.-Q.; Qiu, B.; Zhang, L.-J.; Qin, J.; Tang, F.-J.; Wang, H.-T.; Li, H.-J.; Hao, Y.-R. Assessing causal estimates of the association of obesity-related traits with coronary artery disease using a Mendelian randomization approach. Sci. Rep. 2018, 8, 7146. [CrossRef] [PubMed]

21. Burgess, S.; Thompson, S.G. Mendelian Randomization: Methods for Using Genetic Variants in Causal Estimation; Taylor and Francis: Hoboken, NJ, USA, 2015; ISBN 9781466573178.

22. Pott, J.; Bae, Y.J.; Horn, K.; Teren, A.; Kühnapfel, A.; Kirsten, H.; Ceglarek, U.; Loeffler, M.; Thiery, J.; Kratzsch, J.; et al. Genetic Association Study of Eight Steroid Hormones and Implications for Sexual Dimorphism of Coronary Artery Disease. J. Clin. Endocrinol. Metab. 2019, 104, 5008-5023. [CrossRef] [PubMed]

23. Scholz, M.; Henger, S.; Beutner, F.; Teren, A.; Baber, R.; Willenberg, A.; Ceglarek, U.; Pott, J.; Burkhardt, R.; Thiery, J. Cohort Profile: The Leipzig Research Center for Civilization Diseases-Heart Study (LIFE-Heart). Int. J. Epidemiol. 2020, 49, 1439-1440h. [CrossRef] [PubMed]

24. Loeffler, M.; Engel, C.; Ahnert, P.; Alfermann, D.; Arelin, K.; Baber, R.; Beutner, F.; Binder, H.; Brähler, E.; Burkhardt, R.; et al. The LIFE-Adult-Study: Objectives and design of a population-based cohort study with 10,000 deeply phenotyped adults in Germany. BMC Public Health 2015, 15, 691. [CrossRef] [PubMed] 
25. Auton, A.; Brooks, L.D.; Durbin, R.M.; Garrison, E.P.; Kang, H.M.; Korbel, J.O.; Marchini, J.L.; McCarthy, S.; McVean, G.A.; Abecasis, G.R. A global reference for human genetic variation. Nature 2015, 526, 68-74. [CrossRef]

26. Zhang, Y.; Jin, S. Mitigating placental injuries through up-regulating DAF in experimental APS mice: New mechanism of progesterone. Clin. Exp. Immunol. 2019, 197, 376-386. [CrossRef] [PubMed]

27. Apostolakis, E.M.; Riherd, D.N.; O'Malley, B.W. PAC1 receptors mediate pituitary adenylate cyclase-activating polypeptide- and progesterone-facilitated receptivity in female rats. Mol. Endocrinol. 2005, 19, 2798-2811. [CrossRef] [PubMed]

28. Lieberman, A.P.; Friedlich, D.L.; Harmison, G.; Howell, B.W.; Jordan, C.L.; Breedlove, S.M.; Fischbeck, K.H. Androgens regulate the mammalian homologues of invertebrate sex determination genes tra-2 and fox-1. Biochem. Biophys. Res. Commun. 2001, 282, 499-506. [CrossRef]

29. Hewetson, A.; Chilton, B.S. Progesterone-dependent deoxyribonucleic acid looping between RUSH/SMARCA3 and Egr-1 mediates repression by c-Rel. Mol. Endocrinol. 2008, 22, 813-822. [CrossRef]

30. Yadav, R.; Petrunak, E.M.; Estrada, D.F.; Scott, E.E. Structural insights into the function of steroidogenic cytochrome P450 17A1. Mol. Cell. Endocrinol. 2017, 441, 68-75. [CrossRef]

31. Atif, F.; Patel, N.R.; Yousuf, S.; Stein, D.G. The Synergistic Effect of Combination Progesterone and Temozolomide on Human Glioblastoma Cells. PLoS ONE 2015, 10, e0131441. [CrossRef]

32. Bardin, C.W.; Brown, T.; Isomaa, V.V.; Jänne, O.A. Progestins can mimic, inhibit and potentiate the actions of androgens. Pharmacol. Ther. 1983, 23, 443-459. [CrossRef]

33. Raudrant, D.; Rabe, T. Progestogens with antiandrogenic properties. Drugs 2003, 63, 463-492. [CrossRef]

34. Kurt, B.; Karger, C.; Wagner, C.; Kurtz, A. Control of renin secretion from kidneys with renin cell hyperplasia. Am. J. Physiol. Renal Physiol. 2014, 306, F327-F332. [CrossRef] [PubMed]

35. Ruth, K.S.; Day, F.R.; Tyrrell, J.; Thompson, D.J.; Wood, A.R.; Mahajan, A.; Beaumont, R.N.; Wittemans, L.; Martin, S.; Busch, A.S.; et al. Using human genetics to understand the disease impacts of testosterone in men and women. Nat. Med. 2020, 26, 252-258. [CrossRef]

36. Del Jimenez Rio, M.; Moreno, S.; Garcia-Ospina, G.; Buritica, O.; Uribe, C.S.; Lopera, F.; Velez-Pardo, C. Autosomal recessive juvenile parkinsonism Cys212Tyr mutation in parkin renders lymphocytes susceptible to dopamine- and iron-mediated apoptosis. Mov. Disord. 2004, 19, 324-330. [CrossRef]

37. Wilson, C. Identify Polymorphisms Associated with Risk for the Development of Myopericarditis following Smallpox Vaccine. 2012. Available online: https:/ / www.immport.org/shared/study/SDY26 (accessed on 15 June 2021).

38. Dolzan, V.; Prezelj, J.; Vidan-Jeras, B.; Breskvar, K. Adrenal 21-hydroxylase gene mutations in Slovenian hyperandrogenic women: Evaluation of corticotrophin stimulation and HLA polymorphisms in screening for carrier status. Eur. J. Endocrinol. 1999, 141, 132-139. [CrossRef]

39. Israel, S.; Weinrib, L.; Weintrob, N.; Miller, K.; Brautbar, C. Distribution of the V281L mutation of the CYP21 gene in Israeli congenital adrenal hyperplasia patients and its association with HLA-B14. Pediatr. Endocrinol. Rev. 2006, 3 (Suppl. 3), $447-450$.

40. Gbadegesin, R.A.; Adeyemo, A.; Webb, N.J.A.; Greenbaum, L.A.; Abeyagunawardena, A.; Thalgahagoda, S.; Kale, A.; Gipson, D.; Srivastava, T.; Lin, J.-J.; et al. HLA-DQA1 and PLCG2 Are Candidate Risk Loci for Childhood-Onset Steroid-Sensitive Nephrotic Syndrome. J. Am. Soc. Nephrol. 2015, 26, 1701-1710. [CrossRef] [PubMed]

41. Zheng, H.-Y.; Li, Y.; Dai, W.; Wei, C.-D.; Sun, K.-S.; Tong, Y.-Q. Imbalance of testosterone/estradiol promotes male CHD development. Biomed. Mater. Eng. 2012, 22, 179-185. [CrossRef]

42. Dai, W.; Ming, W.; Li, Y.; Zheng, H.-Y.; Wei, C.-D.; Rui, Z.; Yan, C. Synergistic Effect of a Physiological Ratio of Estradiol and Testosterone in the Treatment of Early-stage Atherosclerosis. Arch. Med. Res. 2015, 46, 619-629. [CrossRef] [PubMed]

43. Pelletier, G.; Dupont, E.; Simard, J.; Luu-The, V.; Bélanger, A.; Labrie, F. Ontogeny and subcellular localization of 3 betahydroxysteroid dehydrogenase ( 3 beta-HSD) in the human and rat adrenal, ovary and testis. J. Steroid Biochem. Mol. Biol. 1992, 43, 451-467. [CrossRef]

44. Meier, M.; Möller, G.; Adamski, J. Perspectives in understanding the role of human 17beta-hydroxysteroid dehydrogenases in health and disease. Ann. N. Y. Acad. Sci. 2009, 1155, 15-24. [CrossRef] [PubMed]

45. Eriksson, A.L.; Perry, J.R.B.; Coviello, A.D.; Delgado, G.E.; Ferrucci, L.; Hoffman, A.R.; Huhtaniemi, I.T.; Ikram, M.A.; Karlsson, M.K.; Kleber, M.E.; et al. Genetic Determinants of Circulating Estrogen Levels and Evidence of a Causal Effect of Estradiol on Bone Density in Men. J. Clin. Endocrinol. Metab. 2018, 103, 991-1004. [CrossRef]

46. Simonetti, L.; Bruque, C.D.; Fernández, C.S.; Benavides-Mori, B.; Delea, M.; Kolomenski, J.E.; Espeche, L.D.; Buzzalino, N.D.; Nadra, A.D.; Dain, L. CYP21A2 mutation update: Comprehensive analysis of databases and published genetic variants. Hum. Mutat. 2018, 39, 5-22. [CrossRef]

47. Orentreich, N.; Brind, J.L.; Vogelman, J.H.; Andres, R.; Baldwin, H. Long-term longitudinal measurements of plasma dehydroepiandrosterone sulfate in normal men. J. Clin. Endocrinol. Metab. 1992, 75, 1002-1004. [CrossRef] [PubMed]

48. Szymczak, J.; Milewicz, A.; Thijssen, J.H.; Blankenstein, M.A.; Daroszewski, J. Concentration of sex steroids in adipose tissue after menopause. Steroids 1998, 63, 319-321. [CrossRef]

49. Mo, Q.; Lu, S.; Simon, N.G. Dehydroepiandrosterone and its metabolites: Differential effects on androgen receptor trafficking and transcriptional activity. J. Steroid Biochem. Mol. Biol. 2006, 99, 50-58. [CrossRef] 
50. Morales, A.J.; Haubrich, R.H.; Hwang, J.Y.; Asakura, H.; Yen, S.S. The effect of six months treatment with a $100 \mathrm{mg}$ daily dose of dehydroepiandrosterone (DHEA) on circulating sex steroids, body composition and muscle strength in age-advanced men and women. Clin. Endocrinol. 1998, 49, 421-432. [CrossRef] [PubMed]

51. Nestler, J.E.; Barlascini, C.O.; Clore, J.N.; Blackard, W.G. Dehydroepiandrosterone reduces serum low density lipoprotein levels and body fat but does not alter insulin sensitivity in normal men. J. Clin. Endocrinol. Metab. 1988, 66, 57-61. [CrossRef] [PubMed]

52. Jankowski, C.M.; Gozansky, W.S.; van Pelt, R.E.; Wolfe, P.; Schwartz, R.S.; Kohrt, W.M. Oral dehydroepiandrosterone replacement in older adults: Effects on central adiposity, glucose metabolism and blood lipids. Clin. Endocrinol. 2011, 75, 456-463. [CrossRef]

53. Hautanen, A.; Adlercreutz, H. Pituitary-adrenocortical function in abdominal obesity of males: Evidence for decreased 21hydroxylase activity. J. Steroid Biochem. Mol. Biol. 1996, 58, 123-133. [CrossRef]

54. Cakir, E.; Doğan, M.; Topaloglu, O.; Ozbek, M.; Cakal, E.; Vural, M.G.; Yeter, E.; Delibasi, T. Subclinical atherosclerosis and hyperandrogenemia are independent risk factors for increased epicardial fat thickness in patients with PCOS and idiopathic hirsutism. Atherosclerosis 2013, 226, 291-295. [CrossRef]

55. Houser, S.L.; Aretz, H.T.; Quist, W.C.; Chang, Y.; Schreiber, A.D. Serum lipids and arterial plaque load are altered independently with high-dose progesterone in hypercholesterolemic male rabbits. Cardiovasc. Pathol. 2000, 9, 317-322. [CrossRef]

56. Mondragón-Ceballos, R.; García Granados, M.D.; Cerda-Molina, A.L.; Chavira-Ramírez, R.; Hernández-López, L.E. Waist-to-Hip Ratio, but Not Body Mass Index, Is Associated with Testosterone and Estradiol Concentrations in Young Women. Int. J. Endocrinol. 2015, 2015, 654046. [CrossRef]

57. Aragam, K.G.; Jiang, T.; Goel, A.; Kanoni, S.; Wolford, B.N.; Weeks, E.M.; Wang, M.; Hindy, G.; Zhou, W.; Grace, C.; et al. Discovery and systematic characterization of risk variants and genes for coronary artery disease in over a million participants. medRxiv 2021. [CrossRef]

58. Gaudl, A.; Kratzsch, J.; Bae, Y.J.; Kiess, W.; Thiery, J.; Ceglarek, U. Liquid chromatography quadrupole linear ion trap mass spectrometry for quantitative steroid hormone analysis in plasma, urine, saliva and hair. J. Chromatogr. A 2016, 1464, 64-71. [CrossRef]

59. Affymetrix. Axiom ${ }^{\mathrm{TM}}$ Analysis Suite; Thermo Fisher Scientific. Available online: http://www.affymetrix.com/support/technical/ byproduct.affx?product=axiomanalysissuite (accessed on 25 October 2021).

60. Howie, B.N.; Donnelly, P.; Marchini, J. A flexible and accurate genotype imputation method for the next generation of genomewide association studies. PLoS Genet. 2009, 5, e1000529. [CrossRef] [PubMed]

61. Dilthey, A.; Leslie, S.; Moutsianas, L.; Shen, J.; Cox, C.; Nelson, M.R.; McVean, G. Multi-population classical HLA type imputation. PLoS Comput. Biol. 2013, 9, e1002877. [CrossRef]

62. Affymetrix. Axiom ${ }^{\mathrm{TM}}$ HLA Analysis; Thermo Fisher Scientific. Available online: http://www.affymetrix.com/support/technical/ byproduct.affx?product=axiom_hla (accessed on 25 October 2021).

63. Chang, C.C.; Chow, C.C.; Tellier, L.C.; Vattikuti, S.; Purcell, S.M.; Lee, J.J. Second-generation PLINK: Rising to the challenge of larger and richer datasets. Gigascience 2015, 4, 7. [CrossRef]

64. Purcell, S.; Chang, C. PLINK 2.0. Available online: www.cog-genomics.org/plink/2.0/ (accessed on 25 October 2021).

65. Zerbino, D.R.; Achuthan, P.; Akanni, W.; Amode, M.R.; Barrell, D.; Bhai, J.; Billis, K.; Cummins, C.; Gall, A.; Girón, C.G.; et al. Ensembl 2018. Nucleic Acids Res. 2018, 46, D754-D761. [CrossRef] [PubMed]

66. Battle, A.; Brown, C.D.; Engelhardt, B.E.; Montgomery, S.B. Genetic effects on gene expression across human tissues. Nature 2017, 550, 204-213. [CrossRef]

67. Buniello, A.; MacArthur, J.A.L.; Cerezo, M.; Harris, L.W.; Hayhurst, J.; Malangone, C.; McMahon, A.; Morales, J.; Mountjoy, E.; Sollis, E.; et al. The NHGRI-EBI GWAS Catalog of published genome-wide association studies, targeted arrays and summary statistics 2019. Nucleic Acids Res. 2019, 47, D1005-D1012. [CrossRef]

68. Barbeira, A.N.; Dickinson, S.P.; Bonazzola, R.; Zheng, J.; Wheeler, H.E.; Torres, J.M.; Torstenson, E.S.; Shah, K.P.; Garcia, T.; Edwards, T.L.; et al. Exploring the phenotypic consequences of tissue specific gene expression variation inferred from GWAS summary statistics. Nat. Commun. 2018, 9, 1825. [CrossRef] [PubMed]

69. Thomson, G.; Single, R.M. Conditional asymmetric linkage disequilibrium (ALD): Extending the biallelic r2 measure. Genetics 2014, 198, 321-331. [CrossRef] [PubMed]

70. Altman, D.G.; Bland, J.M. Interaction revisited: The difference between two estimates. BMJ 2003, 326, 219. [CrossRef]

71. Benjamini, Y.; Bogomolov, M. Selective inference on multiple families of hypotheses. J. R. Stat. Soc. Ser. B Stat. Methodol. 2014, 76, 297-318. [CrossRef]

72. Burgess, S.; Dudbridge, F.; Thompson, S.G. Combining information on multiple instrumental variables in Mendelian randomization: Comparison of allele score and summarized data methods. Stat. Med. 2016, 35, 1880-1906. [CrossRef]

73. Peterson, C.B.; Bogomolov, M.; Benjamini, Y.; Sabatti, C. Many Phenotypes Without Many False Discoveries: Error Controlling Strategies for Multitrait Association Studies. Genet. Epidemiol. 2016, 40, 45-56. [CrossRef]

74. Chinn, S. A simple method for converting an odds ratio to effect size for use in meta-analysis. Stat. Med. 2000, 19, 3127-3131. [CrossRef] 